\title{
Nine Drawings: seriality, postphenomenology and the force of time
}

\author{
Dr Joe Graham, Lecturer in Drawing, Falmouth University.
}

Keywords: drawing; phenomenology; postphenomenology; variations; seriality; temporality; repetition; Minimalism; Bergson; Ihde

\begin{abstract}
This article describes a piece of practice-led drawing research titled: Nine Drawings (2016). Treated as a first-person investigation combining serial drawing, Bergsonian philosophy and a postphenomenological methodology, the purpose is to test the idea of research through drawing by seeking to represent the enigmatic Bergsonian notion that time acts as a force. The methodology employs serially developed drawing to 'record' (represent) the drawers experience of time 'passing'. Treated as a form of praxis which is reflected upon in the drafting of this paper, the process of drawing centres around the effort to draw biro lines 'in time' to a ticking metronome. The metronome is set ticking at various increasing tempos, each represented by a different coloured biro ink, and the results displayed across a series of nine graph paper sheets. In conceptual terms, time is interpreted according to Bergson's philosophy of la durée (duration), while the series is largely assessed using the phenomenological method of variations. Considered in terms of research, the assessment seeks both an invariant and a multistable understanding of the phenomenon under consideration - the experientially derived idea that time acts as a force. The nine drawings are presented individually after the conclusion for the reader to refer to, whilst being presented once as a full series. The results of this multifaceted investigation are reported at the end, and offer potential insights into the way in which research through drawing might operate when art and philosophy are combined.
\end{abstract}

Figure 1. Nine Drawings (full series)

\section{Introduction}

Let's begin with a question: how might a soberly repetitive, yet serially developed drawing express the Bergsonian notion that time acts as a force? And further to this: how might the response to such a question be sensibly presented to those who examine this kind of drawing in tandem with the writing it inspires? Functioning as a report on practice, this article drafts my reply to the query above, thinking it through and presenting it as a piece of practice-led drawing research titled: Nine Drawings (2016). Undertaken with the aim to produce both an interesting series of drawings and to appreciate how research through drawing might operate, Nine Drawings is grounded in the Husserlian inspired, postphenomenological methodology of Don Ihde (2012), Henri Bergson's (1911/1998) superlative philosophy of la durée, and the serially described Minimalist approach to drawing redolent of the late 1960s (Coplans 1968, Eshoo 2008). In asking this question, Nine Drawings makes use of the physicality of graph paper, pencil, coloured biro pens, plus a portable mechanical metronome. And of course - the experience of time.

In fact, Nine Drawings makes use of two understandings of time, conceptually speaking. The first kind indicates the duration of time I, the drawer in question, directly encounter as 'passing' during the act of drawing itself. In this instance, my subjective 
experience of time spent drawing is 'recorded' via the act of drawing coloured lines on graph paper 'in time' to the objectively perceived ticking of a metronome. The second understanding of time is more indirect; it refers to the experience involved in writing, wherein the thinking about how to interpret this serially developed act is drafted and redrafted, both during and after its completion. As a written report, this article makes use of both understandings of time, but the physical articulation through drawing of Bergson's élan vital - what Suzanne Guerlac $(2006,81)$ aptly calls the "creative force of time" - refers to the first kind only.

The primary aim of this process is to see if Bergson's theoretically described notion can be discerned in the drawings themselves, using Don Ihde's (2012) postphenomenological methodology to help organise the various elements such an enterprise demands. To that end Nine Drawings is an unashamedly speculative undertaking, combining a hybrid philosophy with a practitioner's approach in order to test the idea of research through drawing - a concept I believe in wholeheartedly, but only on the basis it must be proven to exist. The nine drawings that make up this series are spaced regularly throughout the article, presented to the reader as the observable outputs of my attempt. Saying this means I consider these drawings as empirical i.e. observable forms of evidence, offered alongside the written argument to draft my thoughts for the reader in combinatory terms. However, the written aspect is not to be overemphasised, for the function of this article is to reflect on this process driven work as praxis, in the truest sense of the term, wherein the practical application of theory is put to the test via the act of drawing itself.

\section{Overview}

In Part One I will situate the work for the reader by providing a broad definition of certain key terms that underpin my approach. This will include a precis of the Rawsonian (1969/1987) definition of drawing I employ, an overview of the Husserlian (1931/2012) phenomenological apparatus underpinning my (current) attitude towards conducting research through drawing, and the Minimalist inspired, serially developed artwork that informs my aesthetic sensibilities. This is followed by Part Two. Here I will describe in more specific detail the theory that frames this particular investigation - both in terms of Bergson's understanding of time and in terms of Ihde's (2012) postphenomenological methodology. Ihde presents an astute, practical and contemporary understanding of phenomenological philosophy, bringing up to date some of Husserl's more applicable ideas whilst adding a few useful additions for practitioners like myself. In Part Three I will describe how the preceding theory is applied in practice, via a detailed description of this work as praxis i.e. in terms of both the drawings themselves and the process used. I will also present the two main findings of this investigation as they relate to my postphenomenological methodology - one 'invariant' and the other 'multistable' - before making some concluding remarks.

The first finding is Husserlian in scope, and relates to the specific question of what these drawings might invariantly tell me about the way time acts as a force, derived from direct observation of the drawn marks themselves. The second finding is inspired by Ihde, and seeks to reflect on the way in which the serial form of Nine Drawings represents a playfully multistable understanding of both drawing and time, understood in artistic terms. On this account, Nine Drawings constitutes a serially developed drawing in a manner not 
unlike Sol LeWitt's Incomplete Open Cubes (1974), whereupon the understanding of the work is distributed across the series as a whole, rather than found within any single iteration.

LeWitt's working method also provides some other sources of inspiration - both in terms of the instructional approach used within his famous wall drawings, wherein various assistants produced them on his behalf, and in terms of the time such instructional activity 'takes up' as an act of drawing. Indeed, looking at one example of LeWitt's work from 1971, Wall Drawing 86: Ten thousand lines about 10 inches $(25 \mathrm{~cm})$ long, covering the wall evenly (Cross and Markonish 2009, 142), the viewer is invited to think about how much time such an undertaking involves. The sheer force of exertion over time that drawing ten thousand lines requires is almost beyond comprehension... but perhaps only if we consider such work to have been undertaken singularly. Once we reflect on the fact that a group of assistants often did the heavy lifting for LeWitt (in terms of carrying out the drawing activity itself), then the notion of how temporality is represented and interpreted within these drawings becomes related to the idea of subjectivity in a rather different way.

Regardless, such an observation does lead to the inevitable conclusion that although the series Nine Drawings is drawn only by me, it should be perfectly possible for others to follow the instructions laid down here and produce a similar set of drawings in a manner akin to LeWitt's approach. Such a methodology might then reveal itself to be truly repeatable in practical terms, providing a means for comparing results, and potentially enhancing the understanding of how to rigorously enact practice-led research as a result.

\section{Nine Drawings}

As a serially developed drawing, Nine Drawings (2016) constitutes an example of process driven phenomenology-in-practice. Each of the nine drawings in this series measures $297 \mathrm{x}$ 420mm (A3), produced on Canson Blue 90gsm millimetre drawing paper (graph paper). On each individual drawing is presented a framework of six horizontal lines drawn in pencil, bisected by a vertical column of two more pencil lines. Along each horizontal pencil line there appears a series of vertical coloured biro lines, appearing in either red, green or blue ink. These are the biro lines I have drawn 'in time' to the tick of a mechanical metronome, set ticking at three increasing tempos $-60,120$ and $180 \mathrm{bpm}$ (beats per minute) respectively. The different colours correspond to the different tempos drawn-to. The green biro lines are drawn in time to the $60 \mathrm{pbm}$ setting, the blue biro lines are drawn in time to the $120 \mathrm{bpm}$ setting, and the red biro lines are drawn in time to the $180 \mathrm{bpm}$ setting.

Physically speaking, each of these metronome settings can be described as having exerted a certain force upon me - in simple terms, the effort required to 'keep time' by drawing lines 'in time' to the ticking metronome increased with the increase in tempo. While this process will be explained in further detail in Part Three, the question I asked myself during the investigation was: will the variety of drawings present any real evidence for this link which I perceive between the physical increase of effort required to draw lines, and the concept of time understood as a force? And if so - how might this be understood?

The reason there are nine drawings relates to the degree of sufficiency reached at a certain point in the investigation, related to the question(s) above. By 'sufficiency' I mean that certain outcomes emerged and suggested themselves ready to be drafted out and reported upon here. Again, this will be explained in more detailed terms, but suffice to say that the 
number nine represents the number of variations attained at a certain point in an on-going investigation. Acquiring intermittent findings through variations is the purpose of my work it is what I seek when I draw. However, this series (and others like it) can and will advance in number beyond the nine iterations discussed here, for such findings are never the end, but merely the beginning for new questions to be asked in new ways. Referring to them as empirical forms of evidence means I consider these drawings as 'data' generated in support of my argument. As Nine Drawings functions as a piece of practice-led research this last element is crucial, for it permits coherent checking of my epistemological claims by others who read and view my work.

\section{Part one: situating the work}

\section{Drawing}

To sensibly conduct my investigations through drawing, I must begin with a working definition of drawing, understood in both practical and theoretical terms. In an effort to keep things simple, I understand 'drawing' to mean that which is, "produced by a point that moves" (Rawson 1969/1987, 15). The point can be thick or thin, hard or soft, made by a brush or a hand or a cloth dipped in ink. But this point must be intentionally moved i.e. rendered mobile with a degree of intention (purpose) on the part of the drawer. This is Philip Rawson's description of drawing, which in turn emerges from Paul Klee's (1925/1953) rather more famous version: the 'active line' on a walk, moving freely, wherein, "the mobility agent is a point, shifting its position forward" $(1925 / 1953,16)$. Although there are many other interpretations of drawing that a practitioner might usefully choose to frame their investigations, Rawson's position presupposes a useful degree of simplicity for an otherwise complex investigation. As movement of the point produces the drawn line, 'line' becomes both the physical evidence for the act of drawing and the conceptual underpinning of 'drawing' per se, regardless of whether the result is considered pictorial or abstract in representational terms. I consider this element of ambiguity very useful indeed, because I often need to defer the question of what is/isn't represented within the drawings for as long as I can (for reasons connected to my methodology, which I will detail shortly).

From Rawson's moving point, I take another step: the drawn line tells the time which the point 'took up' in its passage across a surface in quite specific terms (Graham 2016). While this might seem a rather banal observation for those more interested in the question of what drawing represents in pictorial terms, I find the temporal underpinning to drawing intriguing. Why? Because before it represents a real or imagined scene out 'beyond' the surface of the picture plane, the present grain of drawing (noun) always already re-presents the prior act of drawing (verb) which produced it. In other words: the time taken in making drawings is re-told when viewers draw out an interpretation of them as drawings, and this temporal duality is reflected in the dualistic term drawing (indicating both the verb and the noun).

Perhaps thinking along similar lines, David Musgrave describes in his succinct catalogue essay for the exhibition Living Dust (2004) how the encouragement to 'look through' drawings, coupled with their material slightness, mean they tend to, "collude in their own disappearance" (Musgrave 2004, 10). In taking this position, Musgrave moves away 
from the question of representation towards the suggestion that, "drawing is about both the materiality of the materials used, and the almost immateriality of line and dust" (Musgrave $2004,7)$. If we substitute the phrase 'immateriality of dust' for the immateriality of a concept like Bergson's 'force of time', Musgrave's description of drawing begins to build upon Rawson's moving point. For if such 'immateriality' is materialised within the form, weight and tone of all lines produced via a point that moves, then shouldn't we also speak of drawing as the force of time, given the manner in which the topic always already reappears?

The idea that drawing 'speaks' (Tormey 2011) in a such a particular way animates those who try to articulate their ideas through it, for it touches upon the relationship of drawing to writing (Chorpening, et al. 2012) and the limits of both in describing our world. Placing the convoluted topic of whether or not drawing constitutes a 'language' (Hill 1967) to one side, I link writing and drawing as forms of inscription via the manner in which we experience time. For me, the reciprocal act of giving and receiving underpinning the structure of graphein is the taking and telling of time. The act of sequentially producing marks in order 'to write' or 'to draw' mimics the flow of duration, where each successive moment responds to the previous whilst indicating the next. Catherine de Zegher (2010) indicates this idea more broadly, where, "the first mark not only structures the blank page as an open field but also defines it temporally, as the drawing's marks follow one another in time" (de Zegher and Butler 2010, 23).

\section{Phenomenology}

In broadly epistemological terms, this is a phenomenological investigation inspired by the thinking of Edmund Husserl (1931/2012). As such, I address my questions in principal by seeking an invariant understanding of the phenomenon under consideration - in this case, the Bergsonian idea that time acts as a force. 'Invariant' simply means: that which does not vary. Invariants are deduced from within a range of variants that belong together i.e. a variety of views of the same object seen under different conditions are understood to invariably present 'the object', or in my case, a series of drawings which in their variety look to represent a singular thing or idea. In methodological terms, variations must be placed "on parade" (Depraz 1999, 101) in order for that which is invariantly understood about them to emerge. This approach explains why I produce serially developed drawings - I need to generate a variety (series) of responses for this method to function in a sensible manner.

In following this approach, I am trying to elucidate something important, elemental, or perhaps even 'essential' about the phenomenon under consideration. However, this understanding of invariant is itself reliant on comprehending the subtle manner in which Husserl conceives the difference between 'fact' and 'essence'. As Natalie Depraz $(1999,101)$ so beautifully describes it, "for Husserl, fact (Tatsache) is in consequence abstract and the essence, concrete." In other words - while I may decide to myself that the notion of time as a force is clearly evident within the fact of this drawing here, or clearly evident within the fact of that drawing there, the essence of this idea can always be found elsewhere and otherwise. This means I must search for the invariant as a possible understanding - something that can be understood by others on the basis of being a possibility discovered in multiple ways, rather than anything 'definitive'. This vital clarification of Husserl's original motivation for doing phenomenology is also offered by Ihde (2012) as a means to support his own multistable, 
'postphenomenological' approach. Indeed, the act of seeking possible, yet important understandings through the method of variations is succinctly described by Ihde $(2012,23)$ in the following terms

Variations "possibilize" phenomena. Variations thus are devices that seek the invariants in variants and also seek to determine the limits of a phenomenon. Ideally, of course, variations should be infinite, but, fortunately, this is not necessary since a sufficient number of observations usually yields the essential features.

As this is framed as a postphenomenological investigation, it means I am seeking the multistable finding alongside the invariant. Multistability is a development (of sorts) by Ihde, and refers to accepting the invariance of multiplicity for certain phenomena, beyond that which any supposedly apodictic or 'essential' understanding might describe (Ihde 2012, 45). To be fair to Husserl, he had also developed a term which described something remarkably similar: 'morphological essences' (das morphologische Wesen) described essences that were necessarily inexact, corresponding to "vaguely defined entities" (Moran and Cohen 2012, 212). Both variational method and multistability will be explained in further detail, but suffice to say at this point: within the process of drafting of my ideas, I remain unsure how to interpret the 'force of time' as a phenomenon in relation to drawing. As I am in effect testing variational method in conjunction with drawing as a form of research, then I elect to search for and discuss both forms of phenomenological finding in Part Three.

\section{Minimalism}

In artistic terms, comprehension of serially developed drawing in the manner of Nine Drawings owes a large debt to Minimalism, and more broadly to conceptual abstraction developed since the late 1950s (Chavez 2004). I include within this remit sound works, such as György Ligeti's Poème Symphonique, the 1962 composition for 100 metronomes written during his brief involvement with the Fluxus movement, and the systems of notation introduced by John Cage. Cage's compositions were a formative element of the conceptual art produced during the 1960s, with the score for perhaps his most famous composition, 4'33' (1952) becoming the basis for conceptual pieces in other forms of art. Known as the 'silent piece', the title 4'33" refers to the clock-time duration of the performance, "which (usually) consists of four minutes and thirty-three seconds of silence" (Fetterman 1996, 69). Cage in fact released several variations of this piece, wherein the iteration 4'33" No.2 (1962) came with the instruction to 'perform a disciplined action', again variously interpreted. However, while such works might inspire my decision to enact a metronomic drawing of variable scope and duration, treating it as a 'performance of a disciplined action' in combination with philosophical ideas, they do not indicate what such a work should look like in visual terms.

For an understanding of that, my inspiration comes from the American Minimalists who rose to prominence during the 1960s and early 1970s, all of whom were engaged with questions of repetition and seriality enacted via the medium of drawing, to differing degrees (Eshoo 2008). Practitioners working in this vein, such as Sol LeWitt, Hanne Darboven, William Anastasi, Dorothea Rockburne, Mel Bochner, Carl Andre and Ellsworth Kelly are 
joined more recently by the likes of Allyson Strafella, Jill Baroff, Stefana McClure and Frank Gerritz. Often described via the structure of a series, these works transform the viewers experience of a point traversing a surface into a beguiling reflection on the nature of temporality and human finitude, among other things.

The serial structure of such work is strongly associated with what the philosopher Nicolas De Warren $(2004,11)$ calls the "singular plurality" of the Minimalist approach. This describes serial work in terms of a singularly repeated form that persists across a series of panels, rather than simply the 'plurality of the singular'. This approach describes a loosely connected series of works on a given theme...Monet's series Haystacks (1890) spring to mind. Even in sculptural terms the singular plurality of Minimalism is clear to see - Donald Judd's (2002) Specific Objects are what they are because the serially divided parts remain subordinate to the whole (hence the 'specificity' to which the object refers). Indeed, the allimportant connection between time and the serial approach of Minimalism - or more specifically, between duration and the performative aspect of Minimalism - emerges through the viewers encounter with this structure. Modernist critic Michael Fried noted this underlying connection in his seminal essay Art and Objecthood (1967). Describing Minimalism under his preferred term Literalism, or 'literalist art', Fried writes;

Here finally I want to emphasize something that may already have become clear: the experience in question persists in time, and the presentment of endlessness which, I have been claiming, is central to literalist art and theory is essentially a presentment of endless, or indefinite, duration (Fried 1995, 67, original italics).

In describing the Minimalist concern with temporality as 'paradigmatically theatrical' (1995, 67), Fried outlined his criticism for what he felt was the primary difference between this approach and that of Modernist painting wherein, "at every moment the work itself is wholly manifest" (Fried 1995, 67, original italics). Ignoring for now the difficulties inherent with interpreting a term like 'wholly manifest' in relation to time, Fried's point clearly summarises the reasoning behind using a serially developed methodology to represent the Bergsonian force of time. Bergson's philosophy of la durée (duration), which I will outline shortly, is the concern par excellence with the idea of time experienced as a paradoxical form of flow - the present ('now') is conceived as series of nows along which we cannot return. Much like both Husserl and William James argued, we appear to subsist within a strangely 'moving' or specious present, where time becomes a qualitative multiplicity of states that 'interpenetrate' (Bergson 1913/2001, 108) rather than a set of 'wholly manifest' quantative instants that stand separate and alone.

\section{Part two: Bergson and Ihde}

\section{The Bergsonian force of time}

According to Suzanne Guerlac (2006), one of the primary implications of Bergson's (1913/2001) philosophy of la durée (duration) is that it compels us to, "think dynamically to think in time!" (Guerlac 2006, 139). For Guerlac, the act of thinking in time will reveal Bergson's idea that time acts as a force, especially when we pay close attention to the way in 
which duration is described as a flowing unity in his early work. The Bergsonian concept of 'qualitative multiplicity' (Bergson 1913/2001, 18) underpinning his philosophy is complex, but for the purposes of this investigation through drawing it is sufficient to state that Bergson identifies the principle of causation with the lived experience of temporality. This posits the flowing of time that each one of us subjectively experiences as a vital force (élan vital), coupling the notion of 'becoming' with the sense we all share of growing inevitably older. To justify this claim, Bergson simply points towards the knowledge that we cannot travel backwards in time: "the idea of putting things back in their place at the end of a certain time involves a kind of absurdity, since a turning backwards has never been accomplished in the case of a living being" (Bergson 1913/2001, 153).

Now, while Bergson's philosophy is not considered phenomenological in any classical sense, treating the idea of time as a subjectively perceived form of 'flow' is broadly concordant with Husserl's (1931/2012) work on the topic of consciousness, and the understanding of an operative temporality which underpinned it. To the extent that Bergson feels we endure (or more specifically, perdure) through time without the means to go back on ourselves resonates with the remarkable work Husserl did unpacking the synthesis of protention and retention within the 'living present', described as the phenomenology of the consciousness of internal time (Husserl 1991/2008). To say that a series of serially developed work presented as a unified diversity is uniquely configured to speak about this kind of flow - the lived duration of 'becoming', wherein time is felt to simultaneously approach and recede - is to say that, practically speaking, de Warren's (2004) 'singular plurality' describes the serial artwork as a force that ruptures the idea of instantaneity and the notion of a perpetual present. According to Guerlac (2006), the understanding of time as a force is part of Bergson's larger rejection of determinism within the psychological realm. By confirming the force of duration as a multiplicity, an inner experience wherein, "we discover the flowing of our personality through time" (Bergson 1912/1999, 12), Bergson indicates time as a form of energy, and from which a number of interesting ideas start to emerge.

\section{La durée}

In this sense, "pure duration" is a true Bergsonian concept (1913/2001, 100), for it describes what Bergson feels is simultaneously apparent but easily overlooked in our fixation with quantative thinking, namely: that we appear to experience the flow of time as a qualitative multiplicity, never revisiting the same state twice. Or as Bergson describes it, "no two moments are identical in a conscious being" (Bergson 1946/1992, 164). As a philosopher, Bergson is keen to remind his readership what they intuitively know about time on an experiential level, but only as a means to emphasise the (potentially) radical implications such knowledge contains - that the time we experience as 'passing' is not a spent force, but instead constitutes a form of energy stored by the body for future use as: memory. Guerlac succinctly describes this idea as, "the creative force of time" (Guerlac 2006, 81).

In describing his theory of how memory serves action in the present, Bergson posits free will itself as the force of lived time, given on the basis that duration acts like a cause, or gain, for conscious beings (Bergson 1913/2001, 166). To the extent that time is a gain and acts as a cause, it becomes a force. The sum of memory (the past) slipping into consciousness (the present) provides us the means for deciding how to act, and offers the potential to escape 
the instantaneity of an automatic reaction. As Guerlac says, "this escape, for Bergson, is the essence of what free will means: the possibility of voluntary action as opposed to automatic reaction" (Guerlac 2006, 81). In relation to the vexing question of how one might sensibly define 'free will' for practical purposes connected to drawing, Bergson's own description is insightful. For Bergson (1913/2001, 150), free will is defined as the 'temporal delay' between voluntary action and automatic reaction. Or as Guerlac $(2006,118)$ says, "sight and hearing perceive at a distance and therefore involve a temporal delay and introduce a zone of indeterminacy that enables voluntary action".

The idea of 'temporal delay' is practical because it is measurable, and can be actively introduced into a drawing experiment - for example, by framing the subjective experience of time 'passing' via the objective ticking of a metronome. The varied (and variable) delay between ticks of a metronome set at different tempos could therefore affect the 'zone of indeterminacy' experienced by the drawer during the act of drawing, with this difference reflected in the marks themselves. Such varied differences might then be sensibly compared and contrasted, allowing both invariant and multistable understandings to be sought...whatever they might be.

\section{Ihde's postphenomenological methodology}

In order to develop a coherent, practically orientated methodology that aligns with the Bergsonian theory just outlined, Nine Drawings uses Ihde's (2012) postphenomenological approach for undertaking humanities based research. Less excitingly speculative than Bergson perhaps, Ihde (2012) offers what Bergson doesn't: namely, a clear and concise methodology for examining the vagaries of subjective experience, via methods that are truly observable in their output. Although Bergson's method of 'intuition' is championed by Deleuze (2006), the empirical turn taken by Ihde is arguably less reliant on the subtleties of a poststructuralist i.e. linguistic approach.

Ihde's approach requires any investigation bearing its name to be composed of the following four elements: it must be varied, experimental, intentional and embodied. Described as a non-foundational, anti-essentialist and anti-Cartesian approach (largely in order to counter the idealism associated with Husserl), Ihde's postphenomenology combines the interdisciplinary elements of continental thought with an empirical turn more familiar to those working in the analytic sphere. The aim of using Ihde's four methodological elements is to incorporate Bergson's speculative philosophy with the practice of drawing in more concrete terms. My intention is to make visible the 'zone of indeterminacy' (Guerlac 2006) that constitutes the degree of difference between the automatic and the voluntary which should arise when drawing lines in time to the ticking of a metronome. This embodied degree of difference is Bergsonian free will, and offers a potential means to access the theoretically described force of time via the act of drawing.

In other words: focusing on an observable - and therefore measurable - discrepancy within a series of marks across a series of drawings is itself the effort to 'make visible' the force of time through drawing. Given the sketched-out nature of this claim, the four elements of Ihde's postphenomenology need reiterating in further detail, before describing how they are deployed within the practice of drawing itself. 


\section{The four elements}

Perhaps the most important element within Ihde's methodology is the concept of variations, outlined earlier. Described as either the method of variations, variational practice, variational method, or the 'practice of variational theory', Ihde describes this simply as the method which underpins phenomenology in practice: "in looking at any phenomenon, one must place it within its possibilities, its variations" (Ihde 2008, 6, original italics). Within the history of phenomenology from a Husserlian perspective, variational practice is used in tandem with the prior act of 'bracketing' to search for essential understandings - the 'whatness' (Washeit) of something in terms of necessary predicates (Moran \& Cohen, 2012, p.93). However, as Ihde's postphenomenology adopts an anti-essentialist approach, invariants are searched for in tandem with the idea of multistable structures, be they visual or otherwise, while the notion of bracketing is put to one side (hence not discussed further here, although see [Graham 2016] for details on how it can be deployed in terms of practice-led research).

Since its programmatic inception with the publication of Husserl's Logical Investigations (1900/2008), phenomenology has developed an inter-relational ontology in the form of intentionality. Offering an innovative framework for describing the relation between subject and object (or subject and subject), intentionality comes in a range of different guises. Husserl described consciousness as intentional i.e. consciousness simply means consciousness-of. Heidegger's "being-in-the world" and Merleau-Ponty's être-au-monde are more existential versions that looked to overcome the supposed idealism associated with Husserl's approach, while Ihde sees intentionality as compatible with, "the experientialized interaction between a living organism and its environment... in this case with a human experiential interaction with a lifeworld" (Ihde 2008, 7, original italics).

However, in terms of discussing drawing it would be misleading to think that to 'draw with intention' and 'intentionality' in the phenomenological sense are synonymous, for they are not. Without wishing to be too crude in summarising such a wonderful yet complex concept, the phenomenological notion of intentionality effectively underpins all forms of action that the subject engages in, be they perceptual, conceptual or otherwise. In Husserlian terms, the noesis (act of consciousness) is always already directed towards the noema - the object presented to consciousness (Husserl 1931/2012, 182). Crucially, Husserl understands the noema to indicate something real (reelle) i.e. that which exists over and above the fleetingness of whatever kind of impression of it the subject apprehends (remembering, judging, perceiving the same object as it persists through time). The strange dualism which lies at the heart of intentionality provides a broad and supportive platform to describe the intentional nature of drawing, but only if we consider drawing also as a dualism - wherein the act of drawing 'draws out' an understanding of the object one is drawing, be it perceived or otherwise.

In tune with developments in the social sciences, Ihde's postphenomenology is also rendered emphatically intersubjective in regard to corroborating one's epistemological claims. Clearly one begins with first person experience, but one does not end with it. Instead, "intersubjective checking and critique are also part of the descriptive process" (Ihde 2008, 6, original italics). For me, this intersubjective element is crucial when considering drawing as a form of phenomenological research, not least because much of this type of research has looked to be supported by (to my mind) rather ill-conceived understandings of 
phenomenology. To put it in plainer terms, the question should be continually raised when work like this is presented as to whether drawings are ever able to present anything other than an arrangement of marks across a variety of surfaces, beyond what the drawer thinks their drawings ought to reveal on the basis of what they 'felt' or 'thought' at the time of making. However, the peer-review process involved in submitting articles to reputable journals reinforces the element of intersubjective checking, which means these important questions remain alive and active, if not always resolved.

And finally, there is embodiment. As a non-foundational approach, Ihde's postphenomenology rejects Husserl's supposedly disembodied 'transcendental' attitude, the view from nowhere. Continuing the hermeneutic and pragmatic traditions, Ihde emphasizes both perspectivalism and situated forms of knowing, combining them with a sensitivity to materiality (Ihde 2008, 7). Speaking from the perspective of someone who draws, I find that both embodiment and a sensitivity to materials are taken up intuitively as concrete understandings via the act of drawing itself - the body draws, not the mind alone, and awareness of this is never further away than the simple act of picking up a pencil or pen to draw with.

\section{Part three: combining practice and theory}

\section{Description of practice}

With the foregoing theory and methodology now in place, the practical form of my question can be raised - how do these four elements of Ihde's postphenomenological approach combine with a process of serially developed drawing to explore Bergson's idea that time acts as a force? In an effort to make my response to this question clear, the series Nine Drawings will be described as a process of drawing, presented here as a form of praxis.

As outlined earlier, on each of the nine graph paper drawings is presented a framework of six horizontal lines drawn in pencil, bisected by a vertical column of two more lines, also drawn in pencil. These lines are purely compositional, offering a way to intentionally divide the drawing. Each horizontal line is exactly 20 squares of graph paper wide (not counting the square that the vertical column takes up). Each individual square along this line represents one single second of time. This means that each of the six horizontal lines represents precisely 20 seconds of time. Along each of these horizontal lines I have drawn a series of vertical biro lines 'in time' to a ticking metronome, drawn in either green, blue or red biro ink respectively.

As there are six horizontal lines in each drawing, then each drawing represents ('records') precisely two minutes of time spent drawing. The green biro lines represent lines drawn to the metronome set ticking at $60 \mathrm{bpm}$. The blue biro lines represent lines drawn at $120 \mathrm{bpm}$, and the red biro lines represent lines drawn at 180bpm. Aesthetically speaking, the purpose of changing colour is to simply to make clear which lines correspond to which tempo. The titling of each drawing reflects the arrangement of tempos within it, displaying from left to right the order of tempo, running from the top horizontal line to the bottom i.e. the drawing 60.60.60.60.60.60 represents six horizontal lines all drawn at the 60bpm setting.

Described in terms of process, the purpose of the metronome is to rhythmically 'keep time' for the set duration of 20 seconds which each horizontal line represents, and which I 
draw during. I choose to vary the tempo in order to vary my experience of the same period of time (two minutes) by representing it differently in each drawing, based on the specificities of my approach. To reiterate - for any form of sensible phenomenological analysis to be carried out, a variety of results must to be generated (Ihde 2012, Husserl, 1931/2012). However, all variations must be variations of the same phenomena being examined. As the phenomenon under consideration is Bergson's concept of time as a force, then I need to try and frame this conceptual understanding in a physically consistent, yet observable manner. To that end all nine drawings in the series are framed not just within the same spatial constraints (size of paper, length of pencil lines etc.), but also within the same temporal ones. In other words, each drawing in the series represents precisely two minutes of time spent moving the point across the surface of the paper ('drawing'), although the arrangement of tempos within each of them vary, meaning the same duration of time 'taken up' (recorded) looks different in each according to their formal arrangement.

In embodied terms, once the metronome is set ticking at the desired tempo, I align myself physically with the surface of the paper in such a way that I can complete the act of drawing out a series of biro lines for 20 seconds without needing to stop. Working left to right across the page, I begin drawing the first line in time to the 'tick' of the metronome, and end in time to begin drawing the next line on the next 'tick', repeated in turn. For the $60 \mathrm{bpm}$ variety this means drawing lines at a rate of one line per box per second, i.e. one green biro line is drawn inside each $1 \mathrm{~cm}$ square of graph paper. This is then the presentation, in spatial terms, of one second of time endured by me. For the $120 \mathrm{bpm}$ variety it means drawing two slightly shorter blue biro lines inside one square, because $120 \mathrm{bpm}$ covers two ticks per second, not one. And for the $180 \mathrm{bpm}$ variety it means drawing three very short red biro lines inside each square, moving the point at a rate of three lines per second - a pace that is very hard to sustain!

Each biro line is drawn in a single fluid gesture of the hand. The shrinking length of biro line seen in objective terms across the three colours, from the longer green lines to the shorter reds ones, corresponds to the 'reduced' amount of time I felt I had (subjectively speaking) to draw within. But confusingly, this reduction in length of line is in turn due to the increase in tempo which I directly experienced in embodied terms. For example, during the $60 \mathrm{bpm}$ variety I had a whole second in which to draw a single line, meaning each green biro line has a spatial length that corresponds to this temporal span. For $120 \mathrm{bpm}$ variety I had to draw two lines inside a single second, so each blue line is correspondingly shorter than the green. And for $180 \mathrm{bpm}$ variety I had to try and keep up with the metronome by drawing three red lines within the duration of a single second. As this pace is much harder to sustain, the red lines appear shortest of all.

\section{Seeking the multistable understanding}

Whilst producing Nine Drawings, I was thinking of Ihde's concept of multistability largely in practical terms i.e. thinking 'multi-stable' as indicating a serial approach to making singular work. This is different from Husserl's idea of the invariant, which is sought for only once the variety of drawings are complete and put 'on display', permitting whatever might be (potentially) essential about them to emerge. Seeking a multistable understanding of the force of time through drawing means realising that the three different tempos of 60, 120 and 
$180 \mathrm{bpm}$ could be arranged in a variety of possible ways, both within each drawing and across the series as a whole. To the extent that I physically realised some of these possibilities, Nine Drawings constitutes a serially developed drawing in the Minimalist manner discussed earlier. In artistic terms, this varied/variable attitude is memorably described by Mel Bochner as the 'serial attitude', wherein, "variousness... is sufficient grounds for suggesting we are dealing with an attitude. The serial attitude is a concern with how order of a specific type is manifest" (Bochner 1984, 73).

In physical terms, my serial attitude was manifest in a number of ways. For example, alongside varying the tempo drawn-to, I also varied the formation of tempos as they are drawn-within each drawing, pairing one tempo above or below another according to an overall schema. This schema was based on varying the pairings until a certain symmetry was arrived at. In the first instance, I produced three 'baseline' drawings where I repeated the same tempo on each of the six horizontal lines: 60.60.60.60.60.60 (Fig 2), 120.120.120.120.120.120 (Fig 6), and 180.180.180.180.180.180 (Fig 10). For the next stage of the process I simply varied this schema one stage further, placing two different tempos within a single drawing (Figs 3, 4, 5, 7, 8 and 9) until nine permutations were reached (Fig 1 thus represents the series as a whole). To be sure, the process of varying the number and arrangement of tempos in this series could have continued further than it has, with many more drawings produced as a result of this approach. But if we return to Ihde's point quoted earlier, "ideally, of course, variations should be infinite, but, fortunately, this is not necessary since a sufficient number of observations usually yields the essential features" (Ihde 2012, 23 my italics), it is possible to see why I stopped at nine. I felt I had discovered something important about the phenomenon under consideration - the Bergsonian idea that time acts as a force. With the foregoing material now in place, this discovery is ready to be drafted out as a series of ideas concerning what might invariantly spring forth from the work as it appears.

\section{Seeking the invariant understanding}

Based on the theory underpinning this investigation, I hypothesised that the act of drawing lines freely in time to a ticking metronome would likely affect the ratio of voluntary action to automatic reaction. In the actual experience of drawing, this proved to be correct. At the higher tempo of $180 \mathrm{bpm}$, the degree of freedom within the time I experienced between ticks became compressed, meaning the "zone of indeterminacy" (Guerlac 2006, 118) also contracted - time for conscious reflection shrank, and was gradually replaced by a bodily rhythm that appeared better at 'keeping' time.

If we think of rhythm as describing the body's expectation of a return, then it's possible to see why the frenetic pace required to maintain drawing three lines per second (180pbm) produced the sensation of an embodied rhythm that nevertheless became increasingly hard to sustain. Or as Bergson describes it (1913/2001, 153), "a sensation, by the mere fact of being prolonged, is altered to the point of becoming unbearable". I experienced this rhythm as a kind of automatic reaction across each tick, where my body reacting-to the tempo meant quantative thinking about 'where' to draw each individual line in spatial terms became gradually replaced by a more broadly qualitative feeling of simply 'drawing lines'. The sensation of time as a flowing multiplicity took over, but this realisation appeared only in retrospect, once the event of drawing was over. Experientially speaking, this finding can 
potentially be interpreted as Bergson's force of time, manifesting itself as the 'zone of indeterminacy' between the automatic and voluntary, given on the (phenomenological) basis that drawing lines with intention constitutes an act of free will. Also, with an increase in tempo, duration is felt as a force - the pressure to 'keep time' with the rapidly ticking metronome means the act of drawing lines in time becomes much more difficult to maintain.

But as this is research through drawing, wherein the drawings themselves are treated as a form of data in support of my argument, then the above description needs to be addressed back to the drawings themselves. So, in looking at the series of drawings we see presented here, I ask them - is this notion at all evident in empirical (i.e. observational) terms from within the form of the marks which you present? I would suggest it is, to a degree. Looking at each drawing in the series, we can see the gradual shortening of each biro stroke from green to blue to red - testifies to this idea, wherein the reduction in physical extension (length of line) corresponds to a 'reduction' in time available to draw lines within each square of graph paper as the tempo increased. Such visual data seems to fit with my experience - the act of drawing three little red lines inside a single second is exhausting, and did not suggest time as a purely spatial quantity that could be retraced, but instead spoke of a forceful temporal quality that invariantly became unsustainable the longer it was resisted.

Yet closer inspection of the drawings reveals a further, and somewhat unexpected dimension to this idea. Examining the short red biro lines drawn at $180 \mathrm{bpm}$, we notice first that each red line is individually shorter in length than either the blue or green lines which appear alongside. So far, so expected. However, if we add the length of each of the three red lines which appear inside each square end to end, then they produce a longer red line than either the single green, or the two blue lines joined in similar fashion. As each set of lines (three red, two blue and one green) are all drawn inside the same size square and inside the same duration of time then, paradoxically, it appears the less time there was available to draw each line forced a longer line to emerge. Might this suggest that the Bergsonian force of time somehow manifests itself as the overall lengthening of an otherwise shortening line? A peculiar finding to be sure, but one that appears to occur somewhat invariantly, judging by the evidence on display.

\section{Conclusion}

In proposing these speculative thoughts about how serially developed drawing might investigate the Bergsonian force of time, I have tried to test and extend the idea of research through drawing. My aim has been to make visible the intangibly invisible - exciting ideas like Bergson's that can remain either embedded in the mind alone or embodied without further thought. To be sure, conveying the theoretical framework underpinning the purpose behind these drawings means a body of writing is required, whereupon ideas are drafted and redrafted over time. But even when examined as a standalone artwork hanging in a series on a wall, my hope is that Nine Drawings will indicate through its varied yet colourful and silently repetitive form, evidence of an enquiry that tried to go beyond mimetic representation of something already perceived, or even understood.

To say that Nine Drawings seeks to combine art and philosophy is to say that the purpose of one (philosophy) is put into the service of revealing the specific form of thought that belongs to the other - drawing as an art of time. For me, the specificity of this thought 
both draws and withdraws whenever (and however) I attempt to draw a line around it. I readily admit that I enjoy chasing this enigma, for it keeps me on my toes, so to speak. Always on the lookout for new forms of drawing, and the opportunities they present to tease out new and more developed understandings about the ideas just discussed. Or as George Kubler $(1962 / 2008,29)$ rather more poetically describes it, "the shapes of time are the prey we want to capture".

Figure 2. $\quad 60.60 .60 .60 .60 .60$

Figure 3. $\quad 60.60 .60 .120 .120 .120$

Figure 4. $\quad 60.60 .60 .180 .180 .180$

Figure 5. $\quad 120.120 .120 .60 .60 .60$

Figure 6. $\quad 120.120 .120 .120 .120 .120$

Figure $7 . \quad 120.120 .120 .180 .180 .180$

Figure 8. $\quad 180.180 .180 .60 .60 .60$

Figure 9. $\quad 180.180 .180 .120 .120 .120$

Figure 10. $\quad 180.180 .180 .180 .180 .180$

\section{Bibliography}

Bergson, Henri. 1911/1998. Creative Evolution. Mineola, New York: Dover Publications.

—. 1946/1992. The Creative Mind. The Citadel Press.

-. 1913/2001. Time and Free Will. An Essay on the Immediate Data of Consciousness. Mineola:

Dover Publications.

—. 1912/1999. An Introduction to Metaphysics. Indianapolis: Hackett Publishing Company

Bochner, Mel. 1995. "Serial Art, Systems, Solipsism." In Minimal Art. A Critical Anthology, by

Gregory Battcock, 92-102. Berkeley: University of California Press.

Bochner, Mel. 1984. "The Serial Attitude." In Looking Critically: 21 Years of Art Forum Magazine, by Amy Sandback, 73-77. UMI Research Press.

Chavez, Anja. 2004. Infinite Possibilities: Serial Imagery in 20th-Century Drawings. Wellesley:

Davis Museum and Cultural Centre, Wellesley College.

Chorpening, Kelly, Rebecca Fortnum, Ans Nys, and Peter Morrens. 2012. Drawing-In and Outside-

Writing. RGAP/ Sint-Lucas Visual Arts Ghent.

Coplans, John. 1968. Serial Imagery. The New York Graphic Society in association with the Pasadena Art Museum.

Cross, Susan, and Denise Markonish. 2009. Sol LeWitt: 100 Views. MASS MoCA/Yale University Press.

de Warren, Nicolas. 2004. Ad Infinitum: Boredom and the Play of Imagination. Edited by Anja

Chavez. Davis Museum and Cultural Centre, Wellesley College.

Deleuze, Gilles. 2006. Bergsonism. Cambridge: The MIT Press.

Depraz, Natalie. 1999. "The Phenomenological Reduction as Praxis." In The View From Within:

First-person approaches to the study of consciousness, edited by Francisco Varela and

Jonathan Shear, 95-110. Imprint Academic.

Eshoo, Amy. 2008. 560 Broadway: A New York Drawing Collection at Work, 1991 - 2006. New

Haven: Yale University Press.

Fetterman, William. 1996. John Cage's Theatre Pieces: Notations and Performances. Routledge. 
Fried, Michael. 1995. "Art and Objecthood." In Minimal Art. A Critical Anthology, by Gregory Battcock, 116-147. Berkeley: University of California Press.

Graham, Joe. 2016. "Time taken and time told: Serial drawing as the becoming of now." Drawing:

Research, Theory, Practice (Intellect) 1 (1): 59-78.

Guerlac, Suzanne. 2006. Thinking in Time: An Introduction to Henri Bergson. Ithaca: Cornell University Press.

Hill, Edward. 1967. The Language of Drawing. Prentice-Hall

Husserl, Edmund. 1950/1999. Cartesian Meditations: An Introduction to Phenomenology. Translated by Dorion Cairns. Kluwer Academic Publishers.

—. 1931/2012. Ideas: General Introduction to Pure Phenomenology. Routledge Classics.

—. 1900/2008. Logical Investigations. Vol. 1. Routledge.

—. 1991/2008. On the Phenomenology of the Consciousness of Internal Time (1893 - 1917).

Translated by John Barnett Brough. Springer.

Ihde, Don. 2012. Experimental Phenomenology. 2nd Second: Multistabilities. Albany: The State University of New York Press.

Ihde, Don. 2008. "Introduction: Postphenomenological Research." Human Studies (Springer) 31 (1): $1-9$.

Judd, Donald. 2002. "Specific Objects." In Donald Judd: The Early Works 1956 - 1968, by Thomas Kellein. Distributed Art Publishers.

Klee, Paul. 1925/1953. Pedagogical Sketchbook. Faber and Faber.

Kubler, George. 1962/2008. The Shape of Time: Remarks on the History of Things. Yale University Press.

Moran, Dermot, and Joseph Cohen. 2012. The Husserl Dictionary. Continuum Philosophical Dictionaries.

Musgrave, David. 2004. Living Dust. Norwich: Norwich Gallery, Norwich School of Art \& Design. Rawson, Philip. 1969/1987. Drawing. University of Pennsylvania Press.

Tormey, Jane. 2011. "Afterthought of Drawing." In Drawing a Hypothesis: Figures of Thought, by Nikolaus Gansterer, 241-258. SpringerWienNewYork. 